\title{
THE ROLE OF FORMAL EDUCATION IN DEVELOPING CRITICAL THINKING SKILLS OF ENGINEERING STUDENTS
}

\author{
Andreea Cristina BLÎNDU \\ Lucian Blaga University of Sibiu, Romania \\ e-mail: andreea.cristinaa98@yahoo.com
}

\begin{abstract}
The hereby paper intends to acknowledge and discuss the concept of critical thinking and the influence of this ability on engineering students. The purpose of this research is to establish the criteria according to which some students think more critically compared to other students in the same field of study. Logic is a term that seems simple, although very few know how to access that logical part of the human brain. This research has shown that the students' level of critical thinking is not related to the year of study. Therefore, there are no activities in faculties that have a significant influence on the development of critical thinking. Moreover, it has resulted that female participants think more critically than men participants, but on an insignificant level. Regarding satisfaction in life and its link to critical thinking, it has resulted that unfulfilled students obtained a level of critical thinking higher than the fulfilled ones, a difference that is not of significant relevance. The results of this research are based on two methods: online questioning and focus group.
\end{abstract}

KEYWORDS: critical thinking, gender, cumulative grade point average, life fulfilment

\section{Introduction}

The human brain is imperfect and prone to prejudice, irrationality, distortions and cognitive biases [1]. In most fields, the application of critical thinking is necessary, especially in areas such as engineering, medicine, law, entrepreneurship and journalism. Logical reasoning and the discipline of the mind are qualities that must be acquired through intellectual efforts [2]. This research aims to prove the importance of critical thinking in education as well as in personal life for a better understanding of problems and people.

The critical thinking process helps identifying the arguments that have no basis, no evidence and contain errors or absurdities in the statement. Having critical thinking as their starting point, people manage to be objective. By using critical thinking, people learn how to support their arguments with evidence in order to persuade an audience to agree with them or to support them [3]. In general, this process is very helpful in taking the best decisions as well as in solving various problems.

\section{Setting the context}

\subsection{What is critical thinking}

Dr. Richard Paul, Director of Research and Professional Development at the Center for Critical Thinking, believed that "critical thinking, properly conceptualized, entails understanding the ethical dimension of human life" [4]. This is what critical thinking means if you read behind the words and try to create an image inside your mind that helps you better understand the human behaviour and the empirical reality. Analysing an argument by using critical thinking intensively, guides you through the unknown of the human mind. Additionally, with the help of critical thinking, one has the ability to be able to ascertain another point of view so as to understand people's actions and beliefs. Critical thinking reveals you the path to one's subconscious part of the mind, helping you comprehend the reasons that determine people to act and react in certain ways [5].

Another definition stated by Robert H. Ennis acknowledges critical thinking as being: "the correct way of assessing statements" and "reasonable reflective thinking focused on deciding what to 
believe or do" [6]. Therefore, critical thinking not only develops the ability to identify other perspectives, but it also develops the ability to control their own decisions and actions.

\subsection{Critical thinking in doing business}

As far as business is concerned, critical thinking represents a very effective method in taking decisions, understanding the cause and effect of events and improving communication. When using critical thinking in business, a leader must think logically in order to find, synthesize, analyze, and solve problems [7]. However, acquiring it requires effort and a lot of practice in order to be applied correctly to streamlining product development [8]. In the workplace, critical thinking is in high demand [9], as most of the graduates who are hired fail to identify problems and generate solutions. They do not think logically, being most used to giving memorized answers to questions identified by someone else, but their process of digesting information can be changed through exercises and techniques to stimulate critical thinking [10].

As Bob Schoenberg stated in his book "Critical Thinking in Business: Revised and Expanded Second Edition", the way managers analyze problems, determines the way in which their subordinates will manage the problems that might arise. Managers who use the critical thinking process, encourage the team not only to act likewise, but also to identify and evaluate problems, as well as to generate solutions [11].

\subsection{Measuring methods}

The measuring methods can be found in Professor's William M. Bart paper [12]. There are five tests and each one of them targets the following skills:

(1) California Critical Thinking Skills Test (CCTST): analysis, inference, evaluation, deductive reasoning, inductive reasoning;

(2) Cornell Critical Thinking Test (CCTT): deduction, semantics, credibility, induction-judging conclusions, induction-planning, experiments, definition, assumption identification;

(3) Ennis-Weir Critical Thinking Essay (EnnisWeir): analyzing arguments;

(4) University of Florida Critical Thinking Tests: interpretation, analysis, evaluation, inference, explanation, self-regulation;

(5) Watson Glaser Critical Thinking Appraisal (WGCTA): inference, recognition of assumptions, deduction, interpretation, evaluation of arguments.

\subsection{Skills and competencies of successful people}

Besides the profit that any business is willing to bring, moral values such as ethics, honesty, respect and courage of the one who runs it, define its ultimate success [13]. A true leader, serves his community through social contributions, values the quality of the products/services he offers, takes into account the needs of customers, teaches and encourages his employees, and above all, sets an example for them all.

Combining Noor's Faris paper [14] with the results of "The Future of Jobs Report" [15], made by World Economic Forum, the skills of successful people are as follows: complex problem solving, critical thinking, creativity, people management, coordinating with others, emotional intelligence, judgement and decision making, service orientation, negotiation, cognitive flexibility and many other competencies such as: vision, initiative, optimism, leadership, motivation, and ethics.

\section{Research methodology}

\subsection{Purpose of the research}

In Romania, engineering students are always facing difficult problems regarding mechanics and other logical sciences [16]. They do not always find an answer to a problem, yet there may be a spark in their minds and critical thinking can help turn it into an idea.

This research, which is an exploratory study, aims to provide information on frequent questions or concerns regarding critical thinking.

Is critical thinking an innate talent or a skill that can be built and developed through exercise? Are there differences between thinking according to gender, age, occupation, education and people's mood? Do those who are happy or those who say that the feeling of fulfilment is not yet present in their lives think critically? Do all these criteria have anything in common with critical thinking? Here is the aim of this research: does the percentage of human's logic have limits or can it be increased?

The purpose of this particular research is to find a relevant answer to the following question: does formal education in Romania have an impact on the development of critical thinking [17]?

\subsection{Research hypotheses}

This paper starts from research hypotheses that consist in reflecting critical thinking in academic performance. 
According to a study [18], it was found that critical thinking dispositions have a significant effect on entrepreneurship levels. There are also statistically significant differences in gender, high school and departmental variables with respect to CCTDI (California Critical Thinking Inventory).

Another research regarding the connection of critical thinking and life satisfaction [19], demonstrated that the meaning of life increases along with the dispositions of critical thinking in individuals.

Therefore, the hypotheses of this research are based on the aforementioned research:

I1. Critical thinking is reflected in academic performance.

I2. Critical thinking varies by gender.

I3. The feeling of fulfilment in life is to a greater extent present in the lives of those who think critically.

\subsection{Instruments}

For the first method of this research, the focus was on the score's analysis of ten participants chosen as a focus group. The participants had to solve various problems regarding critical thinking in order to make possible interpreting the level of critical thinking in a more practical way.

The second research method used to determine the level of critical thinking of students was the online questionnaire, which was composed of 25 questions regarding critical thinking and other 6 classification questions. To create and distribute it, the google forms platform was used by activating the option that displays to each participant, the score obtained at the end of the test - according to the grid proposed by those who developed the tool [20].

\subsection{Sampling}

The focus group, the first stage of this marketing research, consists of 10 students from secondary year, belonging to the specialisation of Economic Engineering in Mechanical Domain, Faculty of Engineering, "Lucian Blaga" University, Sibiu. The participants were chosen according to the principle of homogenization of groups based on the results in the admission contest.

The targeted group for the online questionnaire consists of 176 students. The number of students varies from one year of study to another, having in common the Faculty of Engineering, respectively the Economic Engineering in the Mechanical Domain specialization.

\section{Results}

The level of critical thinking is calculated based on the score obtained in the online questionnaire. The mathematic formula used by the tool developers consists in multiplying the obtained score by 100 and dividing the obtained result by the total number of questions. For example, the most obtained score by students was 13 out of 25 questions, which means a critical thinking level of $52 \%$.

Figure 1 represents the level of critical thinking that was obtained by students according to their school's cumulative grade point average. Students with a cumulative grade point average between 9-10 scored the best level on the test, a $56.55 \%$ level out of $100 \%$. Although the ones with a cumulative grade point average between 8-9 follow next as regards their level of critical thinking, one can notice an interruption with respect to the ascending order. Students with the cumulative grade point average below 7, scored better results than those with a cumulative grade point average between 7-8.

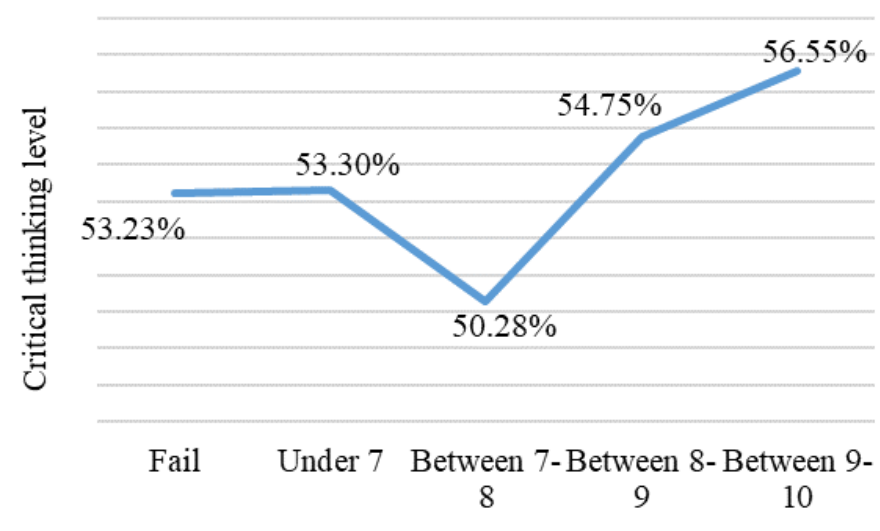

Cumulative grade point average

Fig. 1. The level of critical thinking according to their cumulative grade point average 
Figure 2 represents the level of critical thinking obtained on average by every year of study. With a level of $55.8 \%$, the second year of study obtained the best score and the last year of study, the lowest score of $52.09 \%$.

Figure 3 shows the level of critical thinking according to the feeling of fulfilment in the life of the students. As the figure shows, the unfulfilled students scored $54.75 \%$, whereas those fulfilled scored $53.78 \%$. There was a section for students who are not able to state whether they are fulfilled in life or not. This section scored the lowest level of $51.3 \%$.

Table 1 contains information regarding the score of students per gender and per year of study. Besides the third year of study where male participants scored $54.24 \%$, a level higher with $0.8 \%$ than the female participants, the scores of the females belonging to other years of study, outperformed the males' scores. The "total" row displays the average for all the four years of study according to gender. Females surpassed males, with a level of critical thinking of $55.28 \%$, higher with $5.23 \%$ than the males' level.

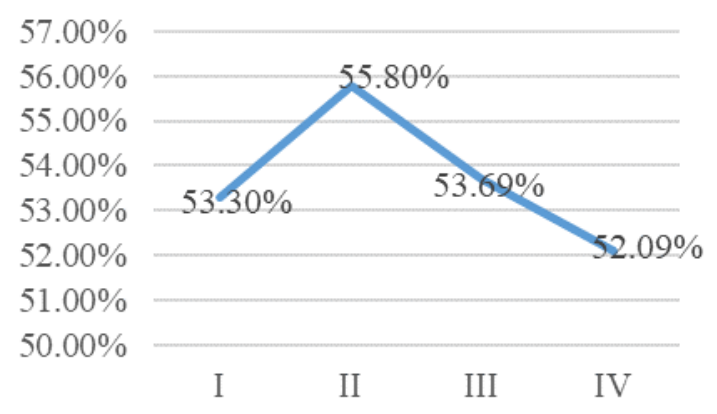

\section{Fig. 2. The level of critical thinking/ year of} study

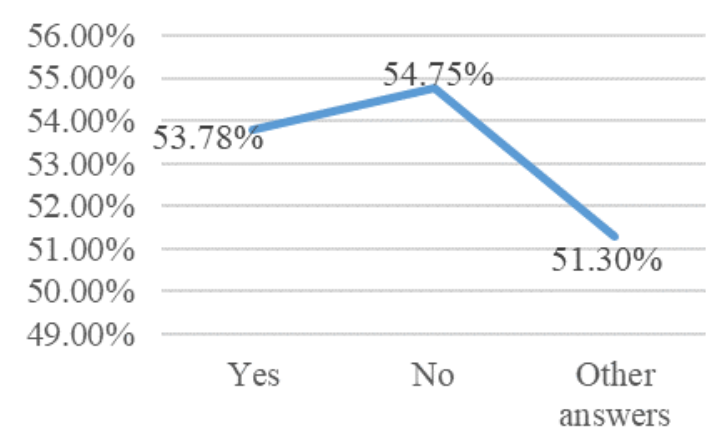

Fig. 3. The level of critical thinking according to fulfilment in life
Table 1. Level of critical thinking/gender/year of study

\begin{tabular}{|c|c|c|}
\hline \multirow{2}{*}{$\begin{array}{c}\text { Year of } \\
\text { study }\end{array}$} & \multicolumn{2}{|c|}{ Gender } \\
\cline { 2 - 3 } & Female & Male \\
\hline I & $56.56 \%$ & $45.64 \%$ \\
\hline II & $56.32 \%$ & $53.12 \%$ \\
\hline III & $53.44 \%$ & $54.24 \%$ \\
\hline IV & $54.8 \%$ & $47.2 \%$ \\
\hline Total & $55.28 \%$ & $50.05 \%$ \\
\hline
\end{tabular}

\section{Discussion}

Following the analysis of the answers given by the focus group participants, the following observations resulted:

- the ability to distinguish a hypothesis from a concrete fact is quite low;

- on the part regarding frames of reference, $3 / 10$ respondents did not understand what a perspective is, confusing it with a state / feeling; what is more, it can be seen that through the role play, good perspectives were found and related to the given situation;

- methodological thinking was one of the strengths of the participants, the arguments being largely strong and convincing;

- the metacognition part is the only one where everyone has found the right answer to the problem that requires teamwork;

- critical thinking games were the ones that stimulated the respondents the most, being much more receptive and curious due to the exposure of the problems in the form of images and diagrams.

Therefore, the participants do not know what critical thinking means and how to develop it, although some acquire it to a greater or lesser extent. Moreover, it has been observed that problems composed of images and text, stimulate critical thinking much more than problems composed only of text.

Regarding the interpretation of the results from the online questionnaire, the average score obtained by the sample of 176 students will be taken into account, this being $13 / 25$ points, so a level of $52 \%$ of critical thinking.

In relation to the students' sense of accomplishment, the highest average level of critical thinking is that of respondents who do not consider themselves fulfilled, namely $54.75 \%$, followed by a small difference from those fulfilled, of $53.78 \%$.

According to statistics, the best results are those given by students whose cumulative grade point average is between 9-10, which means a percentage of $56.55 \%$ that exceeds the average level of critical thinking, followed by students with a cumulative grade point average between 8-9, with a percentage of $54.75 \%$. Also, students with a cumulative grade point 
average below 7 obtained a higher level of critical thinking than those with a cumulative grade point average between $7-8$.

The situation of the results for each year of study vary though the differences between the 4 years of study are insignificant, which shows that there are no teaching activities that have a significant impact on the development of critical thinking.

Regarding the interpretation of the results by gender, out of the 176 students, the female participants obtained on average a percentage of $55.28 \%$, which is higher than that of the male participants with $5.32 \%$. Considering the results belonging to each and every year of study, it is noticed that in the third year of study, males have a critical thinking level of $54.24 \%$, surpassing females with $0.8 \%$. In the other years of study, the female gender has a higher percentage than the male gender with:

- $10.92 \%$, in the first year;

- 3.2 , in the second year;

- $7.6 \%$, in the fourth year.

Summarizing the statistics made by gender, the results of females are better compared to those obtained by males.

\section{Research limitations}

With regard to the limitations of the research, there have been identified the following:

- the online method can affect the respondents' way of answering because they can treat the questions with indifference;

- the surrounding conditions and stress may decrease the concentration of respondents at the time of the questionnaire;

- few classification questions relevant to creating a connection between critical thinking and performance in everyday life; questions related to hobbies, favourite activities, goals in life could be added;

- the small sample size cannot lead to the conclusion of general data;

- the sample's number of females and males is not balanced.

\section{Conclusions and future research directions}

Taking into account all that was mentioned above, two out of three hypotheses have been revealed as being partially true. On the one hand, the hereby research has managed to prove that the correlation between critical thinking and university performance is inexistent. The reason is merely the fact that the level of critical thinking according to the students' cumulative grade point average does not follow an ascending line. On the other hand, another partially true hypothesis has shown that depending on gender, students' critical thinking levels varies, but on an insignificant level.

Last but not the least, the third hypothesis regarding the feeling of fulfillment in life and its influence to critical thinking level has been unconfirmed for the tested sample. The difference between the two categories of people, fulfilled and unfulfilled is insignificant and a definitive statement cannot be made.

Considering the obtained results, the introduction in the academic schedule of activities related to the development of critical thinking through methods such as courses, project-based learning and workshops is highly recommended.

\section{References}

[1]. Hershey H. Friedman, Cognitive Biases that Interfere with Critical Thinking and Scientific Reasoning, SSRN El. J., 2017. [2]. ***, https://www.criticalthinking.org/pages/defining-criticalthinking/766.

[3]. Nonik Indrawatiningsih, Arguments in Critical Thinking Ability, 2018.

[4]. ***, https://www.criticalthinking.org/pages/richard-paul memorial/1231.

[5]. Richard Paul, Linda Elder, A Guide for Educators to Critical Thinking Competency Standards, Rowman \& Littlefield, 2019.

[6]. Robert H. Ennis, Critical Thinking, 2011.

[7]. ***, https://courses.lumenlearning.com/suny-collegesuccesslumen $1 /$ chapter/critical-thinking-skills/.

[8]. ***, https://online.rider.edu/blog/why-is-critical-thinkingimportant-in-business/.

[9]. ***, https://www.weforum.org/agenda/2016/01/the-10-skillsyou-need-to-thrive-in-the-fourth-industrial-revolution/.

[10]. Herbert Nold, Using Critical Thinking Teaching Methods to Increase Student Success: An Action Research Project, International Journal of Teaching and Learning in Higher Education, 2017.

[11]. Bob Schoenberg, Critical Thinking in Business, Revised and Expanded Second Edition, Heuristic Books, 2015.

[12]. William M. Bart, The Measurement and Teaching of Critical Thinking Skills, 2010

[13]. Smarajit Kr Mandal, Ethics in Business \& Corp Governance, Tata McGraw-Hill Education, 2010.

[14]. Noor Faris, Entrepreneurial Skills the Skills You Need to Build a Great Business, 2019.

[15].***, http://www3.weforum.org/docs/WEF_Future_of_Jobs.

[16]. Horia F. Pop, Liana G. T. Pop, Education for engineering students: the case of logic, 2007.

[17]. Ciascai Liliana, Haiduc Lavinia, Is Romanian science school curricula open towards the development of school students' critical thinking skills?, 2009.

[18]. Merve Kırbaşlar, Zeliha Özsoy-Güneş, The Effect of Critical Thinking Disposition on Entrepreneurship Levels: A Study on Future Teachers, 2015.

[19]. Ismail Celik et al., The Link between Critical Thinking Dispositions and Life Satisfaction among University Students, Ozean Journal of Social Science, 8, 3, 2015.

[20]. $* * *$, https://www.assessmentday.co.uk/free/watsonglaser/freetest1/FullTest/. 